\title{
GNSS troposphere tomography based on two-step reconstructions using GPS observations and COSMIC profiles
}

\author{
P. $\mathrm{Xia}^{1,3}$, C. Cai ${ }^{1}$, and Z. Liu $^{2}$ \\ ${ }^{1}$ School of Geosciences and Info-physics, Central South University, Changsha, 410083, China \\ ${ }^{2}$ Department of Land Surveying and Geo-Informatics, Hong Kong Polytechnic University, Hung Hom, \\ Kowloon, Hong Kong, China \\ ${ }^{3}$ GNSS Research Centre, Wuhan University, Wuhan, 430079, China \\ Correspondence to: C. Cai (cscai@ hotmail.com), Z. Liu (1szzliu@polyu.edu.hk)
}

Received: 31 March 2013 - Revised: 20 August 2013 - Accepted: 9 September 2013 - Published: 24 October 2013

\begin{abstract}
Traditionally, balloon-based radiosonde soundings are used to study the spatial distribution of atmospheric water vapour. However, this approach cannot be frequently employed due to its high cost. In contrast, GPS tomography technique can obtain water vapour in a high temporal resolution. In the tomography technique, an iterative or non-iterative reconstruction algorithm is usually utilised to overcome rank deficiency of observation equations for water vapour inversion. However, the single iterative or noniterative reconstruction algorithm has their limitations. For instance, the iterative reconstruction algorithm requires accurate initial values of water vapour while the non-iterative reconstruction algorithm needs proper constraint conditions. To overcome these drawbacks, we present a combined iterative and non-iterative reconstruction approach for the threedimensional (3-D) water vapour inversion using GPS observations and COSMIC profiles. In this approach, the noniterative reconstruction algorithm is first used to estimate water vapour density based on a priori water vapour information derived from COSMIC radio occultation data. The estimates are then employed as initial values in the iterative reconstruction algorithm. The largest advantage of this approach is that precise initial values of water vapour density that are essential in the iterative reconstruction algorithm can be obtained. This combined reconstruction algorithm (CRA) is evaluated using 10-day GPS observations in Hong Kong and COSMIC profiles. The test results indicate that the water vapor accuracy from CRA is 16 and $14 \%$ higher than that of iterative and non-iterative reconstruction approaches, respectively. In addition, the tomography results obtained from the CRA are further validated using radiosonde data. Results
\end{abstract}

indicate that water vapour densities derived from the CRA agree with radiosonde results very well at altitudes above $2.5 \mathrm{~km}$. The average RMS value of their differences above $2.5 \mathrm{~km}$ is $0.44 \mathrm{~g} \mathrm{~m}^{-3}$.

Keywords. Atmospheric composition and structure (Instruments and techniques)

\section{Introduction}

When GPS signals propagate through the troposphere, they experience a distance delay, which is usually called tropospheric delay. The zenith troposphere delay (ZTD) is one of the most important error sources in the GPS signal propagation (Kouba and Héroux, 2001). It contains two parts, namely zenith hydrostatic delay (ZHD) and zenith wet delay (ZWD) (Davis et al., 1985). Since the latter is related to atmosphere water vapour, the distribution of water vapour can be derived from ZWD as long as the ZWD is known. The ZWD is usually obtained by removing ZHD from ZTD that can be estimated using the precise point positioning (PPP) technique (Zumberge et al., 1997; Kouba and Héroux, 2001) or differential positioning technique (Alber et al., 2000; Braun et al., 2001). The ZHD can be precisely computed using empirical models such as Saastamoinen model (Saastamoinen, 1972; Davis et al., 1985).

Generally, GPS signal propagation is subject to the effect of atmospheric anisotropy. Thus, it is more desirable to take the horizontal gradient into account in order to obtain more accurate ZWD (MacMillan, 1995). The slant troposphere delay (STD) may be expressed in the following equations: 
$\mathrm{STD}=\mathrm{SHD}+\mathrm{SWD}+\Delta L_{\text {gradient }}$

$$
\begin{array}{r}
\Delta L_{\text {gradient }}=\frac{1}{\sin (e) \cdot \tan (e)+C} \\
\cdot\left(G_{\mathrm{N}} \cdot \cos (\alpha)+G_{\mathrm{E}} \cdot \sin (\alpha)\right)
\end{array}
$$

where SHD and SWD represent slant hydrostatic delay and slant wet delay, respectively; $e$ and $\alpha$ are the satellite elevation and azimuth angles, respectively; $G_{\mathrm{N}}$ and $G_{\mathrm{E}}$ are the atmospheric horizontal gradient parameters in the northern and eastern directions, respectively; $C$ is a constant and its value is set to 0.003 (Chen and Herring, 1997). The SHD and SWD may be projected to ZHD and ZWD using a Niell mapping function (Niell, 1996). We used the PPP technique to acquire the ZWD in this study rather than the differential technique. Applying Eqs. (1) and (2), the ZWD can be obtained in PPP solutions (Kouba and Héroux, 2001).

Based on the ZWD, the SWD can be calculated using the Niell mapping function (Niell, 1996). After the SWD is obtained, the slant water vapour (SWV) can be computed by a transforming factor (Song, 2004):

$\mathrm{SWV}=\Pi \cdot \mathrm{SWD}$

where $\Pi$ is the conversion factor that is geographically dependent and varies from location to location. It is a dimensionless quantity and a value of 0.1538 (Shi and Gao, 2009) has been used in this study. The SWV will be employed as input data in the tomography of atmospheric water vapour, as presented in the following sections.

The computerised tomography (CT) technology was first applied to ionosphere by Austen et al. (1986) to reconstruct ionospheric electron density distribution in the vertical direction. Flores et al. (2000) successfully obtained fourdimensional (4-D) graphics of the tropospheric refractivity using the tomographic techniques. Since then, GPS water vapour tomography has attracted increasing interest in applications such as climate simulation and natural disaster (Jacob et al., 2007; Falconer et al., 2009). Most importantly, it can be assimilated into numerical weather prediction (NWP) models since it can provide three-dimensional (3-D) distribution of water vapour contents in a high temporal and spatial resolution. Traditionally, the balloon-based radiosonde sounding was employed to obtain water vapour vertical structure in the NWP (Brettle and Galvin, 2003). However, the balloon sounding is highly costly because the balloon cannot be recycled. The 3-D water vapour tomography technique has been widely investigated and significant progresses have been made in recent years. Bender et al. (2011) discussed different implementations of the iterative algebraic reconstruction techniques (ART) and concluded that the multiplicative techniques provide the best results with least processing time. Brenot et al. (2012) exploited horizontal gra- dients of tropospheric delays to improve horizontal and vertical resolution of water vapour density retrieved by the tomographic method. Rohm (2012) presented a methodology to derive the uncertainty of water vapour partial pressure. An unconstrained tomography approach was also proposed by Rohm (2013).

In the tomographic approach, the observation equation is ill-conditioned as satellite signals do not pass through all voxels, causing the non-uniqueness of the tomography solutions. In order to solve this issue, a variety of reconstruction algorithms have been developed. They may be generally grouped into two categories. One is the iterative reconstruction technique (IRT) such as the algebraic reconstruction techniques (ART) (Wen et al., 2010; Bender et al., 2011), the multiplicative algebraic reconstruction techniques (MART) (Stolle et al., 2006; Jin et al., 2008) and the simultaneous iterative reconstruction techniques (SIRT) (Liu et al., 2010). Another is the non-iterative reconstruction technique (NIRT) such as the singular value decomposition technique (SVD) (Flores et al., 2000; Champollion et al., 2005; Notarpietro et al., 2011). In addition, the Kalman filtering (Nilsson and Gradinarsky, 2006) and parameterized approaches (Perler et al., 2011) have also been applied to water vapour tomography. In the NIRT, some constraint conditions such as the horizontal smoothing, vertical smoothing and boundary conditions are usually introduced to overcome the problem of rank deficiency in observation equations. As a result, the accuracy of water vapor estimates is influenced since the constraint conditions cannot truthfully satisfy the practical situation. As for IRT, the voxel values cannot be updated when no rays pass through the voxels. As a result, these voxels still remain their initial status after iterations. Thus, the accuracy of IRT solutions is largely dependent on the initial values. In view of these disadvantages, Notarpietro et al. (2011) jointly used the SIRT-based iterative reconstruction algorithm and the non-iterative reconstruction algorithm with regularisation constraint conditions and non-negative boundary conditions for 3-D troposphere tomography.

We propose a GNSS troposphere tomography based on two steps (non-iterative and iterative reconstructions) using ground-based GPS observations and space-based COSMIC (The Constellation Observing System for Meteorology, Ionosphere and Climate) profiles. In the first step, the noniterative reconstruction is performed in which a priori values of water vapour densities are derived from the COSMIC profiles. In the second step, the iterative reconstruction algorithm is performed using the solutions from the first step as initial values. Instead of using the conventional ART algorithm, we present an improved ART algorithm that can significantly expedite the convergence of iterative process. The use of COSMIC occultation data helps improve the accuracy of the non-iterative reconstruction. The algorithm is tested using 10 days of GPS datasets collected from the Hong Kong Satellite Positioning Reference Station Network (SatRef). The results demonstrate higher accuracy than those using a 
single reconstruction algorithm. The tomography results are further validated using radiosonde data.

\section{Tomographic algorithm}

A combined non-iterative and iterative reconstruction approach for 3-D troposphere tomography is presented in this section. Firstly, the non-iterative reconstruction technique (NIRT) is introduced. Secondly, an improved algebraic reconstruction technique (IART) is proposed. Subsequently, a combined non-iterative and iterative reconstruction approach is proposed using GPS observations and COSMIC profiles.

\subsection{Non-iterative reconstruction technique (NIRT)}

The NIRT is firstly applied to the troposphere tomography in Flores et al. (2000) and its observation model can be expressed as:

$\sum_{i=1}^{\mathrm{nl}} \sum_{j=1}^{\mathrm{nn}} \sum_{k=1}^{\mathrm{nh}} S_{i, j, k}^{q} \cdot \rho_{i, j, k}=\mathrm{SWV}^{q}$

where $S_{i, j, k}^{q}$ is the length that GPS rays span the voxel; the superscript " $q$ " is the satellite index; $\mathrm{SWV}^{q}$ is the slant water vapour for the " $q$ " satellite; The subscript " $i, j, k$ " is the index of voxel in 3-D space, whose water vapour density is denoted as $\rho_{i, j, k}$; "nl", "nn" and "nh" are the numbers of the voxels in the east-west, north-south and vertical directions along the ray path, respectively. Equation (4) can be expressed in a concise matrix form as:

$\mathbf{S} \cdot \rho=\mathrm{SWV}$

The matrix " $\mathbf{S}$ " is under-determined as some voxels have no passing of satellite rays. Thus, constraints have to be introduced to solve this issue. We use the horizontal constraints as provided below (Song, 2004):

$B \cdot \rho=0$

$$
B=\frac{\exp ^{\frac{-d_{i, j}^{2}}{2 \delta^{2}}}}{\sum_{i=1}^{\mathrm{nl}} \sum_{j=1}^{\mathrm{nn}} \exp ^{\frac{-d_{i, j}^{2}}{2 \delta^{2}}}}
$$

where $B$ is the horizontal smoothing based on Gauss distance weighting function whose principle is that the shorter the distance is, the stronger the correlation is (Song, 2004); $d_{i, j}$ is the distance between known and unknown water vapour grids; $\delta$ is the smoothing factor and it is empirically set to 10 in this study (Yu et al., 2010).

In the vertical direction, a pseudo-observation $L$ may be introduced in the following form:

$\mathbf{H} \cdot \rho=L$ where $\mathbf{H}$ is a unit matrix; $L$ is the a priori value of water vapour density. The a priori value can be obtained based on Eq. (9) using the COSMIC occultation data (Song, 2004).

$$
L=\frac{u_{\mathrm{w}}}{R} \cdot \frac{P_{\mathrm{w}}}{T}
$$

where $u_{\mathrm{w}}$ represents the molar mass of the water vapour; $P_{\mathrm{w}}$ is the water vapour partial pressure; $R$ denotes the molar gas constant; $T$ is the atmospheric temperature.

In conjunction with Eqs. (6) and (8), the observation equation for NIRT can be constructed as:

$$
\left[\begin{array}{c}
\mathrm{SWV} \\
0 \\
L
\end{array}\right]=\left[\begin{array}{c}
\mathbf{S} \\
B \\
\mathbf{H}
\end{array}\right] \rho+\left[\begin{array}{c}
\Delta_{1} \\
\Delta_{2} \\
\Delta_{3}
\end{array}\right]
$$

where $\Delta_{i}(i=1,2,3)$ denotes the noise. Using Eq. (10), the water vapour density for each voxel can be obtained by applying the singular value decomposition (SVD) (Ruffini et al., 1998). The detail about the SVD technique may refer to Menke (1989), Hajj et al. (1994) and Ruffini et al. (1998). The SWV values from all valid GPS rays during a period of time are used as input data in Eq. (10). A simple description of this method is provided here.

Suppose $\mathbf{A}$ is an $n \times m$ matrix, it can be decomposed as:

$\underset{n \times m}{\mathbf{A}}=\underset{n \times n}{\mathbf{U}} \underset{n \times m}{\Lambda} \underset{m \times m}{\mathbf{V}^{T}}$

where $\mathbf{U}$ is an $n \times n$ orthonormal matrix; $\Lambda$ is an $n \times m$ diagonal singular value matrix whose elements are positive, sorting in a descending order; $\mathbf{V}$ is an $m \times m$ orthogonal matrix of eigenvectors. After applying the decomposition to $\mathbf{A}$, referred to as $[\mathbf{S}, B, \mathbf{H}]^{T}$ in Eq. (10), the least-squares solution of the water vapour density can be obtained through the generalised inverse:

$\rho=\mathbf{V} \Lambda^{-1} \mathbf{U}^{T} \cdot y$

where $y=[\mathrm{SWV}, 0, L]^{T}$.

The weight values of observations in the left side of Eq. (10) may be determined using the posterior variance component estimation (VCE) method. Considering that the VCE weighting method will bring additional computational load, we simply use an equal weight scheme since the solutions of the non-iterative reconstruction algorithm are only used as the initial values in the IART.

\subsection{Improved algebraic reconstruction technique (IART)}

The algebraic reconstruction technique (ART) (Gordon et al., 1970) is usually used to solve the ill-posed problem in the 3$\mathrm{D}$ tomography. The ART can be described as: 


$$
\begin{aligned}
& \rho_{i, j, k}^{(t+1)}= \\
& \rho_{i, j, k}^{(t)}+\Omega \cdot\left(\mathrm{SWV}^{q}-\sum_{i=1}^{\mathrm{nl}} \sum_{j=1}^{\mathrm{nn}} \sum_{k=1}^{\mathrm{nh}} S_{i, j, k}^{q} \cdot \rho_{i, j, k}^{(t)}\right) \\
& \Omega=\frac{\lambda \cdot S_{i, j, k}^{q}}{\sum_{i=1}^{\mathrm{nl}} \sum_{j=1}^{\mathrm{nn}} \sum_{k=1}^{\mathrm{nh}}\left(S_{i, j, k}^{q}\right)^{2}}
\end{aligned}
$$

where $\Omega$ is a relaxation parameter; $\lambda$ denotes relaxation factor; the superscript " $t$ " represents the $t$ th iteration. It is noted in Eq. (14) that the $\Omega$ remains unchanged in the iterative computing process because $\lambda$ is usually a constant and the vector $S_{i, j, k}$ is also invariable in the iterative process, which will not contribute to increasing the computational efficiency. In order to improve the iterative efficiency, we adaptively adjust the $\Omega$ with $\rho_{i, j, k}^{(t)}$ in the iterative process. We therefore propose an improvement for Eq. (14) as:

$$
\Omega=\frac{\lambda \cdot \sum_{i=1}^{\mathrm{nl}} \sum_{j=1}^{\mathrm{nn}} \sum_{k=1}^{\mathrm{nh}}\left(S_{i, j, k}^{q} \cdot \rho_{i, j, k}^{(t)}\right)}{\sum_{i=1}^{\mathrm{nl}} \sum_{j=1}^{\mathrm{nn}} \sum_{k=1}^{\mathrm{nh}}\left(\left(S_{i, j, k}^{q}\right)^{2} \cdot \rho_{i, j, k}^{(t)}\right)}
$$

In this improved ART (IART) method, the relaxation parameter $\Omega$ is updated with the water vapour density $\rho_{i, j, k}^{(t)}$ at each iterative step. Our results indicate that the IART can significantly increase the computational efficiency and shorten the convergence time.

\subsection{Combined non-iterative and iterative reconstructions}

A combined non-iterative and iterative reconstruction approach for 3-D troposphere tomography is developed using GPS data and COSMIC profiles. First of all, the non-iterative reconstruction technique (NIRT) is applied to derive the water vapour densities at all the voxels using SWV values obtained from GPS data, pseudo-observations derived from the COSMIC profiles and horizontal constraints. Subsequently, the solutions acquired by the NIRT are further utilised as the initial values in the iterative reconstruction technique (IRT) to improve the reconstruction accuracy. In the IRT, the proposed IART algorithm is adopted since it can shorten the iteration time compared to the ART. The same SWV values are used as observations in the IART. The combined reconstruction algorithm has the advantage of avoiding the difficulty of choosing initial values in the iterative reconstruction algorithm. Moreover, it can improve the inversion accuracy of the water vapour density.

We utilised the $P^{3}$ software (Gao, 2004) to obtain the ZWD using GPS data from the Hong Kong SatRef network.
The software has been developed at the University of Calgary, Canada, for PPP processing. The final precise satellite orbit and $5 \mathrm{~min}$ clock corrections from IGS (International GNSS Service) are adopted. The GPS observations have a sampling interval of $5 \mathrm{~s}$ but it is down-sampled to an interval of $30 \mathrm{~s}$ for PPP processing. Thus, the output resolution of the ZWD is $30 \mathrm{~s}$. Along with the estimation of the ZWD, the ambiguity parameters are handled as float values. Based on the PPP technology, the ZWD estimates have an accuracy of about $8 \mathrm{~mm}$ and thereby the corresponding precipitable water vapour (PWV) accuracy is approximately $1 \sim 2 \mathrm{~mm}$ (Kouba and Héroux, 2001). Using the $P^{3}$ software, PPPderived PWV agrees with IGS PWV at an accuracy level of $1.5 \sim 2 \mathrm{~mm}$ (Tao and Gao, 2007).

\section{Tomography results and analysis}

\subsection{Data collection}

The data used in this tomography modelling include groundbased GPS observations and space-based COSMIC profiles. The COSMIC occultation is a joint Taiwan/US science mission for weather, climate, space weather and geodetic research (Yen et al., 2007). Radio occultation technique has been widely applied for meteorology study (Kursinski et al., 1995; Yen et al., 2010; Anthes et al., 2008).

COSMIC provides two types of products, namely, postprocessed data and real-time data products. The former is usually available with a six-week latency and the latter is usually available within a few hours (www.cosmic. ucar.edu). We used the post-processed data products in this study. The COSMIC post-processed data products include six types: raw GPS data, orbit determination, atmospheric profiles, total electron content and ionospheric profiles, scintillations, and tiny ionospheric photometer. Shi et al. (2009) compared the differences between COSMIC Radio Occultation (RO) derived PWV and PPP-inferred PWV and concluded that they are at a comparable accuracy level. Besides, Kishore et al. (2011) made a comparison of specific humidity between COSMIC and radiosonde data. Results indicate a good correlation $(\sim 0.8)$ up to the altitude of $8 \mathrm{~km}$ and suggest that the COSMIC specific humidity profiles are reliable up to $8 \mathrm{~km}$. Wang et al. (2013) compared COSMIC and radiosonde data and revealed that they agreed well with each other. The global mean temperature bias was $-0.09 \mathrm{~K}$ and the global mean humidity bias in the pressure range of 925 $200 \mathrm{hPa}$ is $-0.12 \mathrm{~g} \mathrm{~kg}^{-1}$.

As one type of COSMIC post-processed data products, the "wetPrf" atmospheric profiles offer "wet" pressure, temperature, refractivity and water vapour information. Figure 1 depicts a COSMIC RO event that was captured by the COSMIC-C001 satellite at GPS time 18:19:00 on 20 March 2012. The atmospheric profiles are shown at a maximal height of $40 \mathrm{~km}$. 

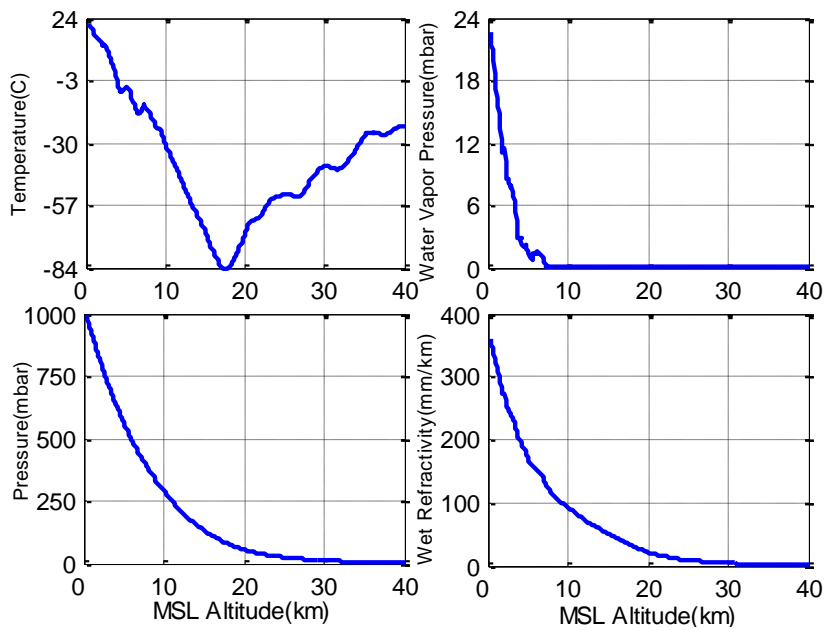

Fig. 1. Atmospheric profiles from COSMIC occultation observations. $X$ axis is Mean Sea Level (MSL) altitude.

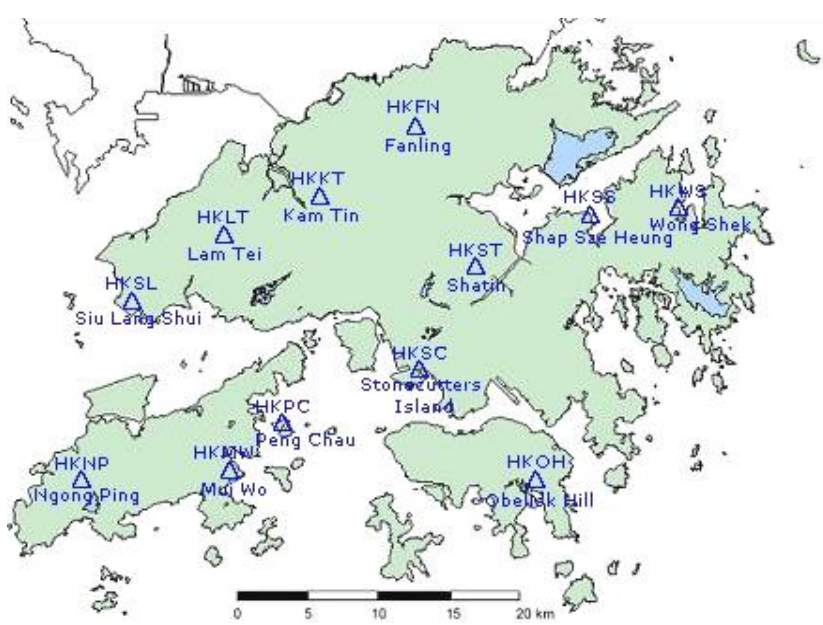

Fig. 2. GPS station distribution in Hong Kong.

The ground-based GPS slant water vapour data are derived from the Hong Kong SatRef network. A total number of 12 continuously operating reference stations, covering an area of approximately 1100 square $\mathrm{km}$, are shown in Fig. 2. The type of receivers employed at all 12 stations is "LEICA GRX1200 + GNSS". These stations are evenly distributed. The GPS data and meteorological data associated with each GPS station are freely available for public access (https://www.geodetic.gov.hk/). The interval of observation data is $5 \mathrm{~s}$ and the interval of meteorological data is $60 \mathrm{~s}$. In the computation of SWV using GPS data, the GPS observations are decimated at an interval of $30 \mathrm{~s}$ and the satellite elevation mask angle is set to 10 degrees.

To verify the effectiveness of the combined reconstruction technique, GPS datasets on 10 days were collected at the time when COSMIC RO events occurred in Hong Kong or near Hong Kong. These COSMIC RO events are given in Ta-
Table 1. COSMIC RO events near Hong Kong.

\begin{tabular}{lrrl}
\hline Date & Long. $\left({ }^{\circ}\right)$ & Lat. $\left({ }^{\circ}\right)$ & COSMIC RO events \\
\hline 10 February 2012 & 114.33 & 22.03 & C001.2012.041.16.53.G32 \\
17 February 2012 & 113.69 & 21.65 & C005.2012.048.11.10.G20 \\
20 March 2012 & 114.61 & 21.88 & C001.2012.080.18.19.G27 \\
16 April 2012 & 113.49 & 22.32 & C002.2012.107.21.22.G29 \\
21 June 2012 & 115.27 & 22.75 & C001.2012.173.14.13.G08 \\
1 July 2012 & 114.51 & 23.08 & C006.2012.183.03.13.G23 \\
5 July 2012 & 112.88 & 21.70 & C002.2012.187.19.30.G08 \\
18 July 2012 & 112.93 & 22.12 & C002.2012.200.04.07.G14 \\
23 July 2012 & 114.21 & 22.31 & C001.2012.205.08.05.G23 \\
30 July 2012 & 114.56 & 22.84 & C001.2012.212.04.53.G20 \\
\hline
\end{tabular}

ble 1 . We examined the quality flag that is included in the wetPrf files. The quality flag in all the ten wetPrf files indicated "bad $=0$ ", suggesting that these profiles passed quality control successfully.

\subsection{Validation of improved algebraic reconstruction technique}

In order to demonstrate the advantage of the improved algebraic reconstruction technique (IART), four RO datasets were processed using the ART and IART algorithms, respectively. They were collected on 10 February 2012 (16:23-16:53 UT), 17 February 2012 (10:40-11:10 UT), 20 March 2012 (17:49-18:19 UT) and 16 April 2012 (20:5221:22 UT). As stated before, the water vapour density values obtained from COSMIC RO events are used as the a priori values. The value of the relaxation factor in the IART, as shown in Eq. (15), is chosen as 0.008 (Wang and Wang, 2011). Wang and Wang (2011) searched the relaxation factor in a range of 0 to 1 and concluded that the best relaxation factor is 0.008 . Suppose $T$ is the RMS (Root Mean Square) of the differences between SWV and $(\mathbf{S} \cdot \rho)$ at the $t$ th iteration, the iteration terminates when the difference of the $T$ values between $t$ th and $(t+1)$ th iterations is smaller than $0.001 \mathrm{~mm}$. Figure 3 illustrates the SWV residuals for the IART and ART algorithms. Figure 4 shows the RMS values of SWV residuals for different number of iterations using the IART and ART algorithms.

In Fig. 3, the average RMS of the SWV residuals is $0.4 \mathrm{~mm}$ for both the IART and ART on the four days. In Fig. 4, the average iterative number is 47 for the IART whereas the average iterative number is 71 for the ART on the four days, following the iterative termination condition. It is clear that IART can significantly improve the convergence rate of the iterative process. We therefore used the IART rather than the ART in the iterative reconstruction of the troposphere tomography. 


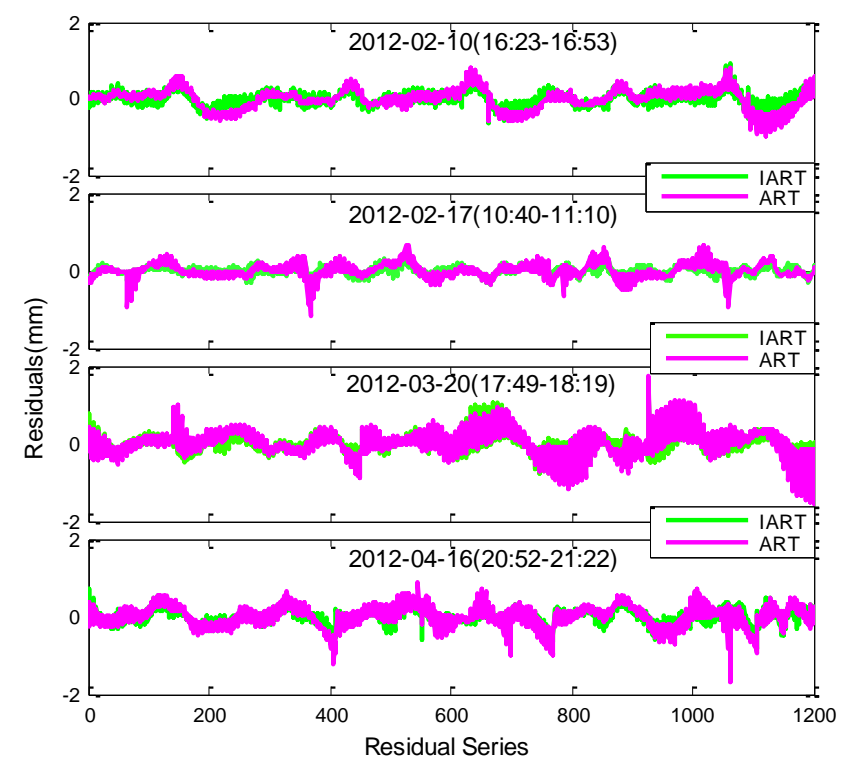

Fig. 3. Slant water vapour (SWV) residuals using GPS data on four days in Hong Kong for IART and ART.

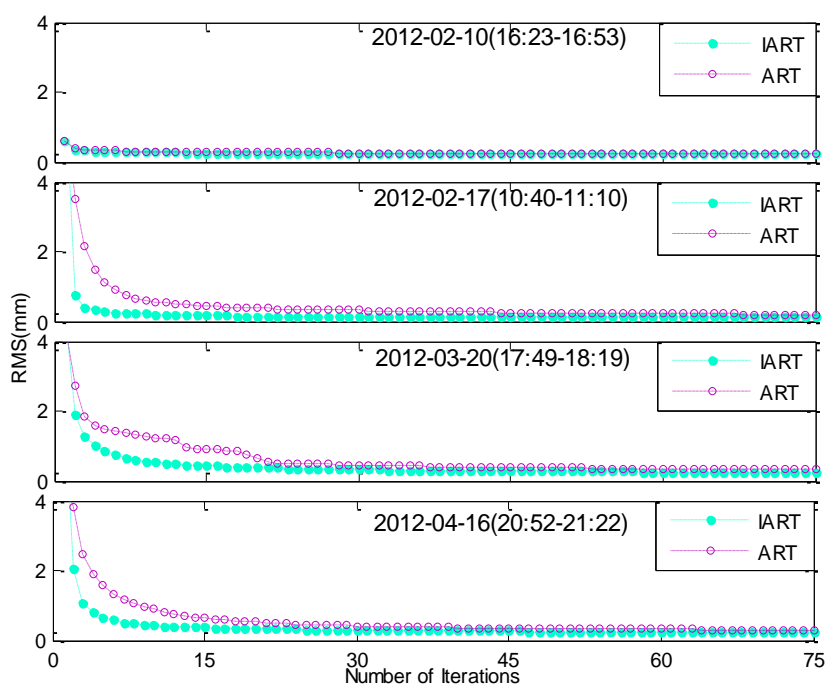

Fig. 4. Iteration rates for IART and ART using GPS data on four days in Hong Kong.

\subsection{Grid division in Hong Kong}

The division of horizontal grids is displayed in Fig. 5. The grid's resolutions in longitude and latitude directions are $0.0625^{\circ}$ and $0.0600^{\circ}$, respectively. The entire Hong Kong area is divided into 8 and 5 grids in the longitude and latitude directions, respectively. The interval of vertical grids is set to $500 \mathrm{~m}$. As the height of troposphere is approximately $10 \mathrm{~km}$, there are 20 layers in the vertical direction. As a result, the total number of voxels in the 3-D space is $8 \times 5 \times 20=800$.

Figure 5 shows the grid distribution covering the Hong Kong SatRef network region. There are several stations such



Fig. 5. Horizontal grid division in Hong Kong. The units in latitude and longitude directions are degrees.

as HKNP, HKMW, HKOH, HKFN and HKWS, which are very close to the edge of the investigated area. As a result, some GPS rays at these stations are likely not to pass through the top grids from the top faces. The observations from these rays may destroy the stability of the tomography model and therefore they are discarded in the tomography computation.

\subsection{GPS tomographic results and analysis}

GPS datasets at 12 stations on 10 days were processed using the $P^{3}$ software to obtain the ZWD. The ZWD is then projected to the SWD using the Niell mapping function. By applying the Eq. (3), the epoch-by-epoch SWV is obtained at the 12 stations. In the computation of non-iterative reconstruction, Eq. (9) is applied to obtain the a priori value of water vapour density using the COSMIC RO data, which is then used as "pseudo-observations" in Eq. (10). Through singular value decomposition, the least-squares solutions of the water vapour density are obtained, as shown in Eq. (12). The estimated solutions of the water vapour density in the noniterative reconstruction are further employed as initial values in the IART. Applying Eqs. (13) and (15), the solutions of the water vapour density are obtained. In the reconstruction computation, the station HKWS is excluded and it is reserved to evaluate the accuracy of the tomography using datasets from other 11 stations.

Considering the temporal variability of water vapour, only SWV that are during half an hour prior to the COSMIC radio occultation events, are used in the troposphere tomography. Therefore, the time resolution of the tomography results is $30 \mathrm{~min}$. The spatial resolution is dependent on the size of the voxel. Figures 6 and 7 demonstrate the tomography results of water vapour based on the combined non-iterative and iterative reconstruction algorithm at four different longitudes on 20 March 2012 and 23 July 2012, respectively. 


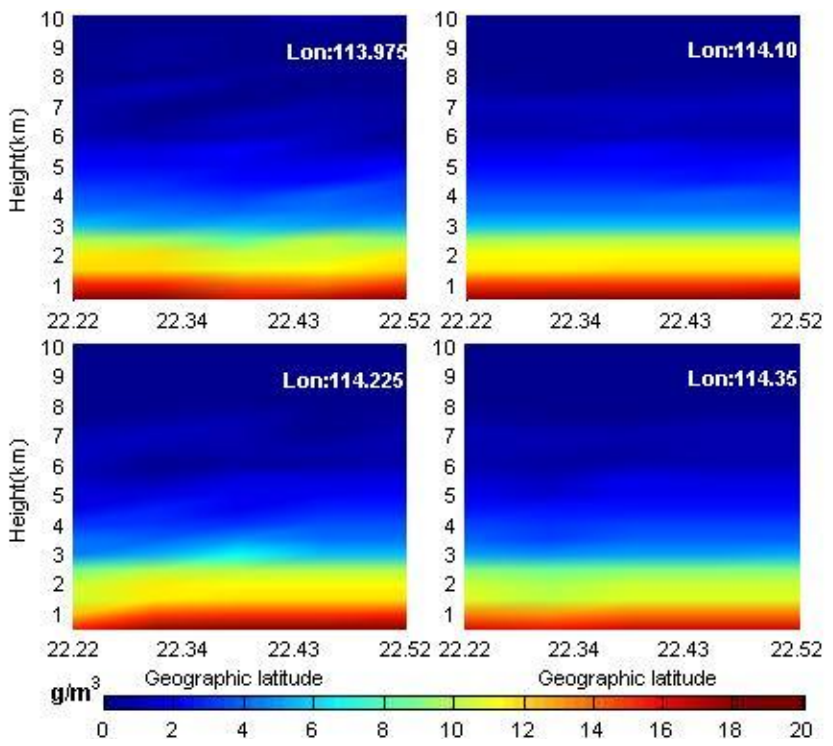

Fig. 6. Vertical profiles of tomographic water vapour at four different longitudes on 20 March 2012.
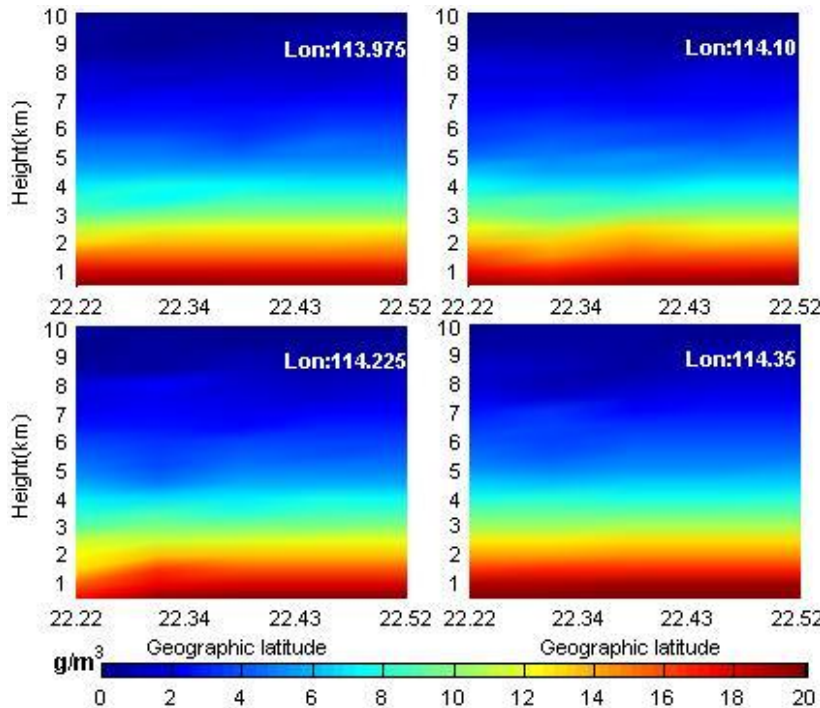

Fig. 7. Vertical profiles of tomographic water vapour at four different longitudes on 23 July 2012.

Figures 6 and 7 describe the water vapour density changes at different latitudes and longitudes. Figure 8 shows the 3$\mathrm{D}$ distribution of water vapour density with a height interval of $500 \mathrm{~m}$. These figures show that the water vapour density remains stable above $5 \mathrm{~km}$ whereas it changes significantly below $5 \mathrm{~km}$. Furthermore, the water vapour density is over $6 \mathrm{~g} \mathrm{~m}^{-3}$ for the height between $2 \mathrm{~km}$ and $5.5 \mathrm{~km}$ on 23 July 2012. By contrast, the water vapour density on 20 March 2012 is mainly concentrated below $3 \mathrm{~km}$. It is noted that the weather conditions were different for the two

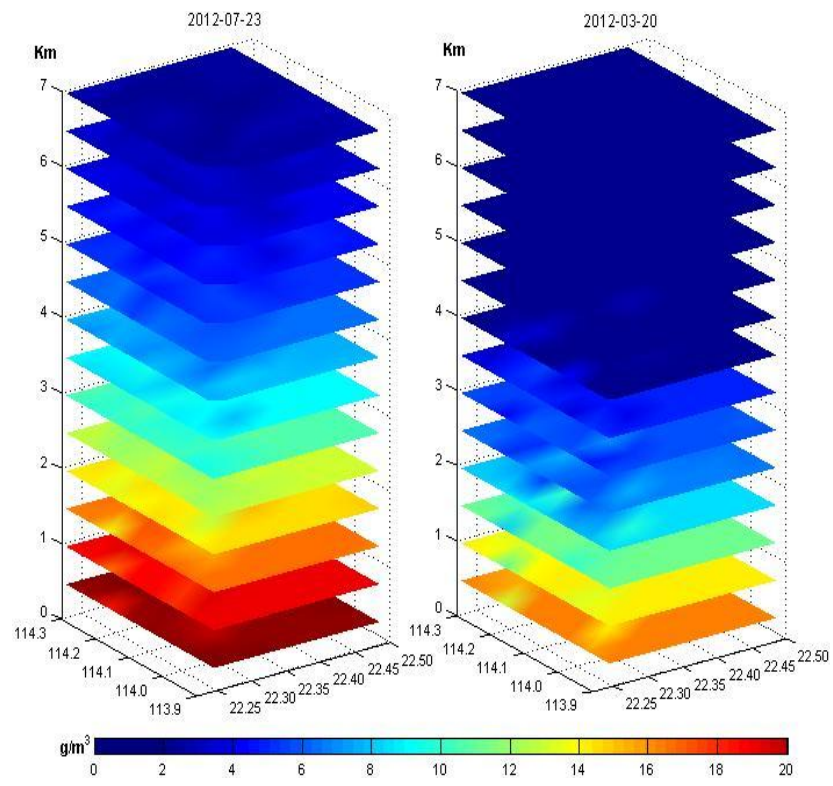

Fig. 8. 3-D tomographic water vapour distribution in Hong Kong on 20 March 2012 and 23 July 2012.

days. It was rainy on 23 July 2012 while it was cloudy on 20 March 2012 in Hong Kong.

In order to test the accuracy of the combined reconstruction algorithm, we compared the RMS statistics of SWV differences using IART, NIRT and CRA, respectively. The SWV differences are the discrepancies between the SWV derived from PPP, which is used as a reference, and the SWV derived from tomography.

There is one radiosonde station in the Hong Kong region. The radiosonde is carried aloft once every $12 \mathrm{~h}$ in Hong Kong, and the sensors on the radiosonde measure profiles of pressure, temperature and relative humidity. Using the information provided by radiosonde, we obtained the a priori values of water vapour density. For comparison purpose, we used radiosonde and COSMIC RO data to obtain the a priori information, respectively, to assess the effect of different a priori information on the performance of combined reconstruction algorithm. A total of 10-day GPS data, radiosonde and COSMIC RO data are processed. As stated before, the dataset at the station HKWS is used to evaluate the accuracy of the tomography. The RMS statistical results for the 10 days are listed in Tables 2 and 3, respectively.

According to the statistical results in the fourth columns of Tables 2 and 3, the mean RMS values of the 10 days is 4.19 and $3.41 \mathrm{~mm}$ for the two cases when the a priori information from the radiosonde data and COSMIC RO data are used, respectively. In Table 2, the CRA improves the accuracy by 20 and $11 \%$, compared to the IART and NIRT, respectively. In Table 3, the CRA improves the accuracy by 16 and $14 \%$, in contrast to the IART and NIRT, respectively. As can be seen from Tables 2 and 3, the CRA approach outperforms the 
Table 2. RMS of differences between PPP-derived and tomography-derived SWV based on the a priori information of water vapour density acquired from radiosonde data $(\mathrm{mm})$.

\begin{tabular}{lrrr}
\hline Date & IART & NIRT & CRA \\
\hline 10 February 2012 & 5.68 & 6.08 & 5.16 \\
17 February 2012 & 1.12 & 1.07 & 0.94 \\
20 March 2012 & 2.34 & 2.33 & 1.84 \\
16 April 2012 & 5.53 & 3.33 & 3.33 \\
21 June 2012 & 3.75 & 2.67 & 2.44 \\
1 July 2012 & 2.73 & 3.33 & 2.44 \\
5 July 2012 & 3.33 & 2.14 & 1.95 \\
18 July 2012 & 8.09 & 7.27 & 6.94 \\
23 July 2012 & 7.69 & 5.57 & 5.36 \\
30 July 2012 & 10.04 & 12.49 & 11.51 \\
\hline
\end{tabular}

Table 3. RMS of differences between PPP-derived and tomography-derived SWV based on the a priori information of water vapour density acquired from COSMIC RO data ( $\mathrm{mm})$.

\begin{tabular}{lrrr}
\hline Date & IART & NIRT & CRA \\
\hline 10 February 2012 & 0.63 & 0.72 & 0.56 \\
17 February 2012 & 4.89 & 4.97 & 4.22 \\
20 March 2012 & 2.94 & 2.96 & 2.20 \\
16 April 2012 & 1.36 & 1.56 & 1.15 \\
21 April 2012 & 3.29 & 2.40 & 2.38 \\
1 July 2012 & 8.15 & 7.79 & 6.10 \\
5 July 2012 & 0.60 & 0.49 & 0.47 \\
18 July 2012 & 3.38 & 3.44 & 3.21 \\
23 July 2012 & 6.02 & 4.56 & 4.42 \\
30 July 2012 & 8.66 & 10.90 & 9.35 \\
\hline
\end{tabular}

IART and NIRT for all 10 days but one on 30 July 2012. In order to examine the reason, Table 4 provides the number of all GPS signal rays, number of valid GPS rays, and number of voxels that have valid GPS rays penetrated through during a period of $30 \mathrm{~min}$. It is noticed that the numbers of valid GPS rays and ray-penetration voxels on 30 July 2012 were much less than other days. As a result, the tomography accuracy using the NIRT is much lower, which in turn affects the tomography accuracy using the CRA algorithm. This suggests that the CRA accuracy is dependent on the quality of the noniterative reconstruction solutions. Comparing Table 2 with Table 3, it is found that COSMIC RO data are more preferable to the radiosonde in most cases as a priori values of water vapour density. Due to the differences in space for the $\mathrm{RO}$ event and the investigated area, the a priori values derived from RO data are not always better than those acquired by the radiosonde data, such as the days on 17 February and 1 July 2012. Although the COSMIC RO data contribute to improving the accuracy of tomography results, the currently available data still have a very low temporal and spatial resolution, which restricts its practical applications. However,
Table 4. Number of all and valid GPS rays and number of voxels that valid GPS rays passed through.

\begin{tabular}{lrrr}
\hline Date & No. of & No. of & $\begin{array}{r}\text { No. of } \\
\text { ray-passed } \\
\text { voxels }\end{array}$ \\
\hline 10 February 2012 & 5901 & 2142 & 446 \\
17 February 2012 & 4621 & 1811 & 453 \\
20 March 2012 & 5883 & 1822 & 396 \\
16 April 2012 & 5348 & 2177 & 393 \\
21 June 2012 & 4110 & 2087 & 384 \\
1 July 2012 & 5283 & 1577 & 380 \\
5 July 2012 & 4121 & 1965 & 480 \\
18 July 2012 & 5870 & 1927 & 441 \\
23 July 2012 & 5815 & 2158 & 389 \\
30 July 2012 & 5912 & 1600 & 349 \\
\hline
\end{tabular}
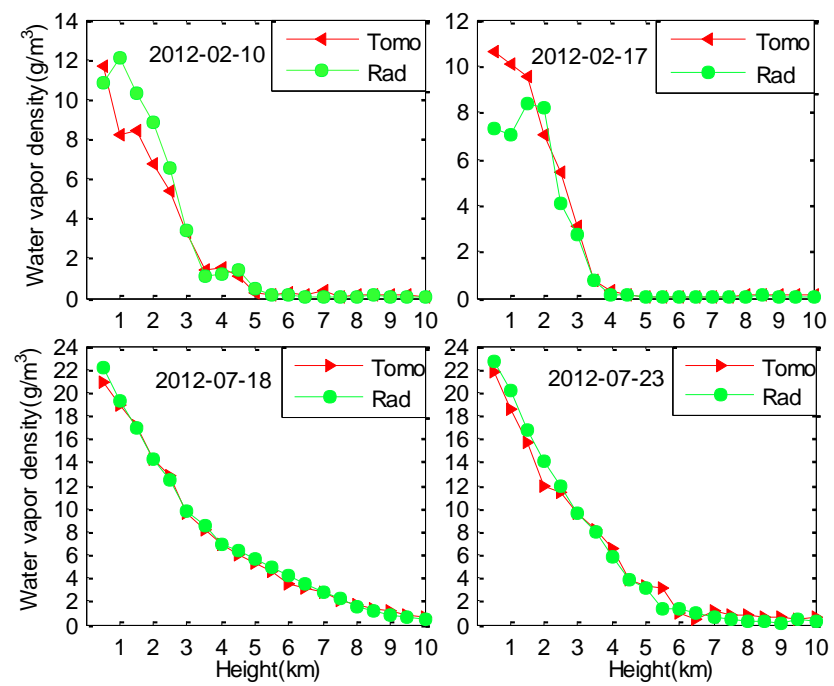

Fig. 9. Comparisons of water vapour densities obtained from tomography (red line) and radiosonde data (green line).

with the advent of the second generation COSMIC occultation and the availability of other RO data in near future, this situation will be improved.

The tomography results shown in Fig. 8 are further validated by the vertical water vapour density derived from radiosonde data. The location of the radiosonde station is latitude $22.31^{\circ}$ and longitude $114.16^{\circ}$. Based on the measurements provided by radiosonde such as pressure, temperature, and relative humidity, the water vapour density values are obtained in different altitudes by linear interpolation. The water vapour density values are then used to evaluate those tomography-derived results using GPS observations and COSMIC profiles. Their comparison results on four days are shown in Fig. 9.

It can be seen that the changing trends of water vapour density at heights above $2.5 \mathrm{~km}$ between tomography-derived 
Table 5. RMS of differences between tomography-derived and radiosonde-derived water vapour densities $\left(\mathrm{g} \mathrm{m}^{-3}\right)$.

\begin{tabular}{lrrr}
\hline Data & $0 \sim 2.5 \mathrm{~km}$ & $2.5 \sim 10 \mathrm{~km}$ & $0 \sim 10 \mathrm{~km}$ \\
\hline 10 February 2012 & 2.25 & 0.22 & 1.34 \\
17 February 2012 & 2.23 & 0.12 & 1.12 \\
20 March 2012 & 2.02 & 0.24 & 1.04 \\
16 April 2012 & 1.41 & 0.41 & 0.79 \\
21 June 2012 & 0.81 & 0.43 & 0.55 \\
1 July 2012 & 1.81 & 0.58 & 1.04 \\
5 July 2012 & 2.78 & 0.56 & 1.47 \\
18 July 2012 & 0.65 & 0.33 & 0.43 \\
23 July 2012 & 1.35 & 0.60 & 0.85 \\
30 July 2012 & 2.39 & 0.85 & 1.38 \\
\hline Mean & 1.78 & 0.44 & 1.01 \\
\hline
\end{tabular}

and radiosonde-derived results have a very good agreement. The RMS value of their differences above $2.5 \mathrm{~km}$ is better than $0.5 \mathrm{~g} \mathrm{~m}^{-3}$ on four days. Larger differences occur at heights below $2.5 \mathrm{~km}$. This is because, on one hand, the tomography inversion and radiosonde data are different in time. As the COSMIC profiles are needed to obtain a priori information in tomography, the tomographic modeling is carried out only when COSMIC radio occultation occurs. The radio occultation occurrence time is usually different from radiosonde launch time. On the other hand, the a priori information derived from the COSMIC radio occultation profiles has lower accuracy in the bottom layer of atmosphere. Table 5 provides the RMS of differences between tomographyderived and radiosonde-derived water vapour densities in three different heights on all the ten days. In terms of the statistical results in Table 5, the average RMS of the differences is $1.78 \mathrm{~g} \mathrm{~m}^{-3}$ below $2.5 \mathrm{~km}$ and $0.44 \mathrm{~g} \mathrm{~m}^{-3}$ above $2.5 \mathrm{~km}$, which again confirms that the tomography-derived water vapour densities agree well with ones derived from radiosonde above $2.5 \mathrm{~km}$.

\section{Conclusions}

A combined non-iterative and iterative reconstruction algorithm (CRA) for water vapour tomography is presented. In the CRA, the water vapour density is obtained following two steps. First, the water vapour density is computed using the NIRT (non-iterative reconstruction technique). Then, the computed values are employed as initial values for the IRT (iterative reconstruction technique) to improve the tomography accuracy. In the IRT, we propose an improved algebraic reconstruction technique (IART), which can significantly reduce the number of iterations and improve the computational efficiency.

We use the precise point positioning (PPP) technique to obtain the tropospheric zenith wet delay (ZWD) from ground-based GPS data. Then it is projected to slant wet delay (SWD) using the elevation angle information of GPS rays. The SWD is further converted into slant water vapour (SWV) using a transforming factor. The space-based COSMIC profiles are used to derive the water vapour density, which is utilised as the a priori information in the NIRT computation.

The 10-day GPS datasets collected from Hong Kong SatRef GPS network and COSMIC occultation products are used to test the proposed approach. The test results demonstrate that the CRA can significantly improve the tomography accuracy over IART and NIRT alone. The improvement rates are 16 and $14 \%$ in contrast to IART and NIRT approach, respectively. The tomography results based on the CRA algorithm are further validated using ten-day radiosonde data. Results indicate that the water vapour densities above the height of $2.5 \mathrm{~km}$ derived by the tomography have a good agreement with radiosonde results, with an average RMS of $0.44 \mathrm{~g} \mathrm{~m}^{-3}$. The water vapour density agreement below the altitude $2.5 \mathrm{~km}$ has an average RMS value of $1.78 \mathrm{~g} \mathrm{~m}^{-3}$, largely depending on the data quality used for tomography modeling.

Acknowledgements. The financial supports from the National Natural Science Foundation of China (No. 41004011; No. 41274039), National Basic Research Program of China (No. 2013CB733303; No. 2012CB957701) and the Hong Kong Research Grants Council (RGC) General Research Fund (GRF) project B-Q28F are greatly appreciated. Zhizhao Liu also thanks the support of Programme of Introducing Talents of Discipline to Universities (Wuhan University, GNSS Research Center), China. The authors would like to acknowledge the Survey and Mapping Office of the Lands Department, Hong Kong Special Administrative Region for providing GPS data and meteorological data from the Hong Kong Satellite Positioning Reference Station (SatRef) Network. The Hong Kong Observatory is appreciated for providing the radiosonde data. The Constellation Observing System for Meteorology, Ionosphere and Climate-1 program is acknowledged for providing COSMIC Radio Occultation data used in this study.

Topical Editor C. Jacobi thanks A. Raabe and one anonymous referee for their help in evaluating this paper.

\section{References}

Alber, C., Ware, R., Rocken, C., and Braun, J.: Obtaining single path phase delays form GPS double differences, Geophys. Res. Lett., 27, 2661-2664, 2000.

Anthes, R. A., Bernhardt, P. A., Chen, Y., Cucurull, L., Dymond, K. F., Ector, D., Healy, S. B., Ho, S. P., Hunt, D. C., Kuo, Y. H., Liu, H., Manning, K., Mccormick, C., Meehan, T. K., Randel, W. J., Rocken, C., Schreiner, W. S., Sokolovskiy, S. V., Syndergaard, S., Thompson, D. C., Trenberth, K. E., Wee, T. K., Yen, N. L., and Zeng, Z.: The COSMIC/FORMOSAT-3 mission: early results, B. Am. Meteorol. Soc., 89, 313-333, doi:10.1175/BAMS89-3-313, 2008. 
Austen, J. R., Franke, S. J., Liu, C. H., and Yeh, K. C.: Applications of computerized tomography techniques to ionospheric research, in: International Beacon Satellite Symposium on Radio Beacon Contribution to the Study of ionization and Dynamics of the Ionosphere and to Corrections to Geodesy and Technical Workshop, Oulu, Finland, 25-35, 1986.

Bender, M., Dick, G., Ge, M., Deng, Z., Wickert, J., Kahle, H. G., Raabe, A. and Tetzlaff, G.: Development of a GNSS water vapour tomography system using algebraic reconstruction techniques, Adv. Space Res., 47, 1704-1720, doi:10.1016/j.asr.2010.05.034, 2011.

Braun, J., Rochen, C., and Ware, R.: Validation of line-of-sight water vapour measurements with GPS, Radio Sci., 36, 459-472, 2001.

Brenot, H., Champollion, C., Deckmyn, A., Malderen, R. V., Kumps, N., Warnant, R., and Mazière, M.: Humidity 3D field comparisons between GNSS tomography, IASI satellite observations and ALARO model, Geophys. Res. Abstr., 14, EGU20124285, 2012.

Brettle, M. J. and Galvin, J. F. P.: Back to basics: radiosondes: part 1- the instrument, Weather, 58, 336-341, 2003.

Champollion, C., Masson, F., and Bouinm, N.: GPS water vapour tomography: preliminary results from the ESCOMPTE field experiment, Atmos. Res., 74, 253-274, 2005.

Chen, G. and Herring, T. A.: Effects of atmospheric azimuthal asymmetry on the analysis of space Geodetic data, J. Geophys. Res., 102, 20489-20502, 1997.

Davis, J. L., Herring, T. A., Shapiro, I. I., Rogers, A. E. E., and Elgered, G.: Geodesy by radio interferometry: effects of atmospheric modeling errors on estimates of baseline length, Radio Sci., 20, 1593-1607, doi:10.1029/RS020i006p01593, 1985.

Falconer, R. H., Cobby, D., Smyth, P., Astle, G., Dent, J., and Golding, B.: Pluvial flooding: new approaches in flood warning, mapping and risk management, J. Flood Risk Manag., 2, 198-208, 2009.

Flores, A., Ruffini, G., and Rius, A.: 4D tropospheric tomography using GPS slant wet delays, Ann. Geophys., 18, 223-234, 2000, http://www.ann-geophys.net/18/223/2000/.

Gao, Y.: P3 user manual (version 1.0), University of Calgary, Canada, available at: http://people.ucalgary.ca/ ygao/images/ P3\%20manual.pdf (last access: 16 October 2013), 2004.

Gordon, R., Bender, R., and Herman, G. T.: Algebraic reconstruction techniques (ART) for three-dimensionan electron microscopy and X-ray photography, J. Theor. Biol., 29, 471-476, 1970.

Hajj, G. A., Ibanez-Meier, R., Kursinski, E. R., and Romans, L. J.: Imaging the ionosphere with the global positioning system, Intl. J. Imag. Syst. Tech., 5, 174-184, 1994.

Jin, S. G., Luo, O. F., and Park, P.: GPS observations of the ionospheric F2-layer behavior during the 20th November 2003 geomagnetic storm over South Korea, J. Geophys. Res., 82, 883892, 2008.

Jacob, D., Brring, L., Christensen, O., Christensen, J., De Castro, M., Dqu, M., Giorgi, F., Hagemann, S., Hirschi, M., Jones, R. Kjellstrm, E., Lenderink, G., Rockel, B., Snchez, E., Schr, C., Seneviratne, S., Somot, S., van Ulden, A., and van den Hurk, B.: An inter-comparison of regional climate models for Europe: model performance in present-day climate, Clim. Change, 81, 8479-8491, doi:10.1007/s10584-006-9213-4, 2007.
Kishore, P., Venkat R. M., Namboothiric, S. P., Velicognaa, I., Bashab, G., Jiang, J. H., Igarashi, K., Rao, S. V. B., and Sivakumar, V.: Global $\left(50^{\circ} \mathrm{S}-50^{\circ} \mathrm{N}\right)$ Distribution of water vapour observed by Cosmic GPS Ro: comparison with GPS Radiosonde, NCEP, Era-Interim, and Jra-25 reanalysis data sets, J. Atmos. Sol.-Terr. Phy., 73, 1849-1860, 2011.

Kouba, J. and Héroux, P.: Precise point positioning using IGS orbit and clock products, GPS Solut., 5, 12-28, 2001.

Kursinski, E. R., Hajj, G. A., Hardy, K. R., Romans, L. J., and Schofield, J. T.: Observing tropospheric water vapour by radio occultation using global positioning system, Geophys. Res. Lett., 22, 2365-2368, 1995.

Liu, S. Z., Wang, J. X., and Gao, J. Q.: Inversion of ionosphere electron density based on a constrained simultaneous iteration reconstruction technique, IEEE T. Geosci. Remote, 48, 2455-2459, 2010.

MacMillan, D. S.: Atmospheric gradients from very long baseline interferometry observations, Geophys. Res. Lett., 22, 10411044, 1995.

Menke, W.: Geophysical data analysis: discrete inverse theory, Revised Edn, International Geophysics Series, 45, Academic Press, New, York, 1989.

Niell, A. E.: Global mapping functions for atmosphere delay at radio wavelengths, J. Geophys. Res., 101, 3227-3246, 1996.

Nilsson, T. and Gradinarsky, L.: Water vapour tomography using GPS phase observation: simulation results, IEEE Trans. Geosci. Remote Sens., 44, 2927-2941, 2006.

Notarpietro, R., Cucca, M., Gabella, M., Venuti, G., and Perona, G.: Tomographic reconstruction of wet and total refractivity fields from GNSS receiver networks, Adv. Space Res., 898-912 ,doi:10.1016/j.asr.2010.12.025, 2011.

Perler, D., Geiger, A., and Hurter, F.: 4D GPS water vapour tomograhpy: new parameterized approaches. J. Geophys., 85, 539550, doi:10.1007/s00190-011-0454-2, 2011.

Rohm, W.: The precision of humidity in GNSS tomography, Atmos. Res., 107, 69-75, 2012.

Rohm, W.: The ground GNSS tomography - unconstrained approach, Adv. Space Res., 51, 501-513, 2013.

Ruffini, G., Flores, A., and Rius, A.: GPS tomography of the ionospheric electron content with a correlation functional, IEEE Trans. Remote Sens. Environ., 36, 143-153, 1998.

Saastamoinen, J.: Atmospheric correction for the troposphere and stratosphere in radio ranging of satellites, in: The Use of Artificial Satellites for Geodesy, Geophys. Monogr., 15, 247-251, 1972.

Shi, J. and Gao, Y.: Assimilation of GPS radio occultation observations with a near real-time GPS PPP-inferred water vapour system, proceedings of ION GNSS, Savannah, Georgia, 2584-2590, 2009.

Song, S. L.: Sensing three dimensional water vapour structure with ground-based GPS network and the application in meteorology, Ph.D. thesis of Shanghai Astronomical Observatory CAS, 80-84, 2004.

Stolle, C., Schlüter, S., Heise, S., Jacobi, C., Jakowski, N., and Raabe, A.: A GPS based three dimensional ionospheric imaging tool: Process and assessment, Adv. Space Res., 38, 2313-2317, 2006.

Tao, W. and Gao, Y.: Real-time water vapour sensing/measurements with precise point positioning algorithm and Canadian Geodetic 
(GPS) network, proceedings of ION GNSS, Fort Worth, Texas, 2890-2897, 2007.

Wang, B. R., Liu, X. Y., and Wang, J. K.: Assessment of COSMIC radio occultation retrieval product using global radiosonde data, Atmos. Meas. Tech., 6, 1073-1083, doi:10.5194/amt-61073-2013, 2013.

Wang, W. and Wang, J. X.: Ground-based GPS water vapour tomography based on algebraic reconstruction technique, J. Comput. Appl., 31, 3149-3156, 2011 (in Chinese).

Wen, D. B., Liu, S. Z., and Tang, P. Y.: Tomographic reconstruction of ionospheric electron density based on constrained algebraic reconstruction technique, GPS Solut., 14, 251-258, 2010.

Yen, N. L., Huang, C. Y., and Chen, J. F.: FORMOSAT-3/COSMIC GPS radio occultation mission: preliminary results, IEEE $\mathrm{T}$. Geosci. Remote, 45, 3813-3825, 2007.
Yen, N. L., Fong, C. J., Chu, C. H., Miau, J. J., Liou, Y. A., and Kuo, Y. H.: Global GNSS radio occultation mission for meteorology, ionosphere and climate, Aerospace Technologies Advancements, Book edited by: Thawar T. A., ISBN 978-953-7619-96-1, Intech, Croatia, 241-258, 2010.

Yu, S. J., Liu, L. T., and Liang, X. H.: Influence analysis of constraint conditions on GPS water vapour tomography, Acta Geod. Cartogr. Sin., 39, 490-496, 2010 (in Chinese).

Zumberge, J. F., Heflin, M. B., and Jefferson, D. C.: Precise point positioning for the efficient and robust analysis of GPS data from large networks, J. Geophys. Res., 102, 5005-5017, 1997. 